\title{
Requests for "inappropriate" treatment based on religious beliefs
}

\author{
Robert D Orr and Leigh B Genesen Loma Linda University Medical Center, California and Lovelace \\ Hospital and University of New Mexico Hospital, Albuquerque, New \\ Mexico, USA
}

\begin{abstract}
Requests by patients or their families for treatment which the patient's physician considers to be "inappropriate" are becoming more frequent than refusals of treatment which the physician considers appropriate. Such requests are often based on the patient's religious beliefs about the attributes of God (sovereignty, omnipotence), the attributes of persons (sanctity of life), or the individual's personal relationship with God (communication, commands, etc).

We present four such cases and discuss some of the basic religious tenets of the three Abrahamic faith traditions as they relate to such requests. We suggest that religious reasons for requesting "inappropriate" treatment are "special" and deserve serious consideration.

We offer guidance to assist clinicians and clinical ethicists as they attempt to resolve these conflicts, emphasising the importance of understanding the religious beliefs of the patient/surrogate and suggesting the assistance of a religious interpreter. We suggest open discussion with patients and families of both the clinical situation and the theological basis for these requests. We also suggest that clinicians use additional religious doctrines or principles from patients' own traditions to balance the reasons behind the requests.

We conclude that most persistent requests for "inappropriate" treatment should be honoured.
\end{abstract}

\section{Introduction}

Conflicts about treatment decisions usually result from differing perceptions of facts (for example dealing with uncertainty), differing emotions (for example time to adjust to impending death), or differing cultural or religious values. Such conflicts can most often be resolved at the bedside using shared decision-making, perhaps with the assistance of an ethics consultant or committee; however, occasionally they must be resolved in court. Most refusal of treatment cases (often incorrectly called "right to

\section{Key words}

Ethics; religion; values. die" cases) have been settled by acknowledging the patient's right to decline treatment when the perceived burdens outweigh the benefits. Recently the converse situation has become more prominent, where the patient or family requests or demands a treatment which the physician feels is "inappropriate". In our experience, such patient demands are now more common than patient refusals. ${ }^{1}$ Physicians occasionally challenge such demands based on medical futility, ${ }^{2}$ medical standards, ${ }^{3}$ patient suffering, ${ }^{4}$ lack of net benefit to the patient, ${ }^{56}$ or cost $^{7}$.

Only a few of the treatment refusal cases have involved religious reasons. A majority of health care professionals have gradually come to agree that treatment refusals based on religious beliefs are rational because the choices are based on valued tenets shared with a faith community, and the individuals making these choices are being consistent in trying to reach their goals. Other authors are unwilling to call religious reasons for treatment refusal "rational", but concede that they are different from wrongheaded "irrational" decisions and call them "non-rational" to give them some credence. ${ }^{8}$ The paradigmatic religiously based treatment refusal is the Jehovah's Witness patient who refuses a potentially life-saving blood transfusion, based on an interpretation of scripture made by his/her faith community. His choice to risk a shortened life in order to follow his understanding of a command from Jehovah is consistent with his eternal goals.

Wreen has proposed that religious reasons for treatment refusal are "special" and should be considered differently from other reasons offered by patients. ${ }^{9} \mathrm{He}$ points out that patient autonomy is accorded prominence for two quite different sets of values - intrinsic values such as privacy and bodily integrity, and extrinsic values such as religious freedom. He goes on to argue that "[i]t's not the truth or falsity of the religious beliefs that the person holds that's relevant so much as that they're his beliefs". Religious values can fit into a rational person's life, and they are special because they involve the meaning of life and have a "... pervasive, supremely important integrating and reconciling 
function . . ." in a person's life. He did not address the issue of religious reasons for demanding "inappropriate" treatment.

Our observation is that, in contrast to the "right to refuse treatment" cases where religion is infrequently an issue, very often a request for "inappropriate" treatment is based on religious beliefs. Some of these requests are based on beliefs about the attributes of God (sovereignty, omnipotence), some on a belief about the attributes of persons (sanctity of life), and others on the individual's personal relationship with God (communication, commands, etc).

In this paper we will present four cases to illustrate demands for "inappropriate" treatment based on the patient's or surrogate's religious beliefs. We will discuss the validity and persuasiveness of these claims; we will support and expand Wreen's contention that religious beliefs are "special" in relation to resolution of differences between patients and physicians; and we will offer an approach to respectful resolution of these dilemmas.

We recognise that the physician's assessment that an intervention is "inappropriate" is both a clinical judgment and a value judgment. For the purposes of this paper we will use the term "inappropriate" treatment to include both a quantitative assessment by the physician, ie the proposed intervention will have no positive impact on outcome, or has a minute likelihood of success with significant burdens, and a qualitative assessment, ie it is outside the bounds of accepted medical practice. The latter may have legal as well as clinical significance. Our focus will be whether a professional judgment of "inappropriateness" should always trump the patient's judgment of what is appropriate based on his or her religious tradition.

For the purpose of this discussion, we accept at face value that these requests are based on religious beliefs. We recognise that some religious motives are deeply and sincerely matters of belief; some individuals, however, use trite religious ideas consciously or unconsciously to cover other motives.

We will limit our discussion to the religious beliefs of the three Abrahamic faith traditions, Judaism, Christianity and Islam. Demands for "inappropriate" treatment based on values espoused by religions other than these three faiths, and those based on non-religious spirituality, are becoming increasingly prevalent in our multicultural society, but they are beyond the scope of this discussion.

\section{Cases and discussion}

CASE 1: "ONLY ALLAH CAN TAKE A LIFE"

The three-and-a-half-year old daughter of a devout Muslim family who have lived in the US for several years has been unresponsive for two weeks from recurrence of a malignant spinal cord tumour for which there is no further treatment available. She also has severe, progressive Adult Respiratory Distress Syndrome. She is in the paediatric intensive care unit (ICU) on multiple organ support, and her primary physician, paediatric intensivist and consulting specialists have all asked the father to allow withdrawal of her current level of life-support. $\mathrm{He}$ demands that all measures continue because "Only Allah can take a life" and he understands his role as her father is to continue all efforts to sustain her biological life.

\section{Vitalism}

This case demonstrates a vitalistic stance based on theological claims. Vitalism is a belief which places the highest value on continuation of biological life. Such a stance is taken by some Muslims, Orthodox Jews, Roman Catholics or fundamentalist Protestants, and is based on the sovereignty of God and the sanctity of human life. Human life is a gift from a sovereign God who has ultimate authority over its beginning and end. Human life is sacred because it was created in God's own image, so that humans are qualitatively different from animals. While there may be broad agreement among the three faith traditions on both the sovereignty of God and the sanctity of human life, there is not agreement on how these doctrines apply in some clinical situations.

A vitalistic stance based on theological beliefs may come from a misunderstanding of the word "value". As Stith has pointed out, sanctity and value are radically different. ${ }^{10}$ Sanctity, or sacredness, means the object is consecrated or set apart, whereas value refers to its worth. While life is sacred, it is also finite, and other things (for example relief of suffering, eternal life with God) may sometimes be of greater value.

Many faith traditions which subscribe to a belief in the sanctity of life also believe in continuity of existence of the individual after biological death. Such life after death is usually felt to be of greater value than the human condition, and is often believed to be a reward for belief or behaviour during human existence. Many who maintain a strong belief in the sanctity of human life would therefore conclude that the vitalistic pursuit of continued human life may at times be inappropriate, having become an idolatrous worship of human life. Others who hold a vitalist stance do not believe in life after death, but rather believe that one of the reasons that life is so precious is its very finiteness.

Another response to the vitalist position is that most faith traditions also believe that God has commanded stewardship, expecting humans to use their bodies and resources wisely. This would imply some expectation of human discernment, decisionmaking and accountability. 
CASE 2: "WE ARE WAITING FOR GOD TO PERFORM A MIRACLE"

A 19-year-old Hispanic male from a devout Roman Catholic family was found to have a posterior fossa medulloblastoma (brain tumour) seven months before his final admission to a tertiary care hospital. It was treated with non-curative debulking surgery, radiation and chemotherapy. In spite of this aggressive treatment, he had progressive deterioration, and he had been unresponsive for three weeks before an ethics consultation was requested. At the time of the request, he was in status epilepticus, he required a ventilator because of lack of respiratory drive, and he was being treated with antibiotics, antihypertensives, and artificially administered fluids and nutrition. $\mathrm{He}$ did not meet the neurological criteria for death. His parents were insisting that full treatment continue because they were waiting for God to perform a miracle.

\section{Miracles}

Many requests for "inappropriate" treatment are based on a belief in miracles which is itself based on two attributes of God, sovereignty and omnipotence. People from many faith traditions believe God is omnipotent, having established the laws of nature and being able miraculously to override those laws. In the holy scriptures of all three Abrahamic faiths, it is recorded that God has intervened supernaturally in the lives of individuals and communities.

Some believe that God used miraculous signs in earlier times, but does not do so now that faith is established. Others believe in continued frequent miraculous events, especially in relation to healing. Some hold so strongly to a belief in supernatural healing that they eschew traditional medical practices entirely, fearing that their use of medicine would indicate a distrust of God's love and power. Most adherents to these three faiths accept traditional medicine as one of God's gifts which enables us to continue to serve our deity.

Belief in God's ability to perform a miracle does not, however, imply that God will perform a miracle in a particular case. Experience tells us that miracles are rare occurrences. God's sovereignty and omnipotence are universal, but their application is particular. Thus it does not follow from a belief in God's miraculous power that we must continue treatment which human reason concludes will not work. If God is sovereign and omnipotent, human choice or action is not needed to achieve God's goals. Exploring the patient/surrogate understanding of the attributes of God will sometimes help him relinquish requests for "inappropriate" treatments based on hope for a miracle.

CASE 3: "GOD TOLD ME HE WILL SURVIVE"

Before this four-month-old boy was born with Down's syndrome and complex anomalies of his heart, his devout Pentecostal parents named him: after an Old Testament patriarch. He had had foung surgical interventions in an effort to prolong his life: but he was now in multi-organ failure with no rea sonable likelihood of survival. For the preceding two weeks, his bedside nurses had urged his physicians to음 persuade his parents to withdraw life support so thate his suffering might cease. When the surgeon $\mathbb{B}$ approached the family with this strong recommen-n dation, they refused to consider withdrawal of lifesupport. They said that God had spoken to his mother through scripture references which con $\overrightarrow{\vec{\omega}}$ tained the patient's first name, and in this mannero had promised her that he would get better as a testi mony to the hospital staff and the community of God's power.

\section{Prophetic messages from God}

Some individuals request "inappropriate" treatment? because they believe they have received a directc message from God. Belief in the ability to receive such prophetic messages from God has been present in many faith traditions in the past, but is moste common in North America today among. Pentecostal Christians. Such communication is believed to be one of the supernatural "gifts of thes Spirit". Both the ability to exercise this gift, and theo carrying out of the content of the message is felt by⿳亠丷厂 some to be contingent upon unwavering faith. Most who maintain a belief in prophetic messages from $\overrightarrow{\hat{\sigma}}$ God, retain as part of that belief that the exercise of 3 this gift and the interpretations of such messages is? subject to communal discernment. Thus the reli-0. gious community of the patient should be involved in these discussions. However, the patient belongs to more than one community, for instance family, social community and medical professional com munity. Perhaps others, therefore, should also haveo a voice.

CASE 4: "SHE'S NOT READY TO DIE"

A 69-year-old non-religious woman was admitted toㅡ. the hospital two weeks earlier with a dissecting aneurysm of her thoracic aorta which had extended both distally causing renal failure and proximally causing cerebrovascular insufficiency. Although the lesion was too extensive to allow surgical repair, her family requested dialysis and other technologicale support to extend her life. She was then physiologi- $-\infty$ cally stable, but had had only partial neurological recovery, and her physicians were certain the aneurysm would rupture fatally at any moment. She्त was able to communicate, but was not able to make? medical decisions. A decision had to be made about either stopping dialysis or surgically inserting a per manent access site for long-term dialysis and seekingo placement in an extended care facility. Based ong previous statements she had made, her daughter andi son were convinced she would choose to stop? 
dialysis. However, her Southern Baptist sister had been "witnessing to her about faith in Jesus" for the two preceding weeks and she believed the patient was nearly ready and was able to make a decision for salvation. She therefore insisted that life-support be continued because "she's not ready to die".

\section{Waiting for salvation}

Some individuals demand "inappropriate" treatment because they are waiting for the patient to make a spiritual decision or perform a ritual which has eternal consequences. Many Christians believe that Jesus left a "Great Commission" commanding them to tell others that salvation and eternal life with God are available only to those who believe in Jesus' sacrificial death and who go on to make a personal decision to repent and accept this gift from God. Failure to make such a decision results in eternal suffering, eternal separation from God, or extinction, according to various interpretations of scripture. Some feel responsible for the eternal damnation of others' souls if they are unable to convince them to make a decision, while others believe they are to offer the information and the responsibility for the decision is between the individual and God. Other faith traditions expect an individual to make some other step of faith, to pray a specific prayer, or to partake in a particular ritual in order to be assured of eternal reward.

\section{Discussion}

On the surface, requests for "inappropriate" treatment seem to resurrect the age-old discussion in medicine of "medical judgment" $v$ "patient autonomy". Is medical judgment simply a scientific conclusion where biological survival is the assumed end? Does the patient's right to accept or decline a specific treatment according to his or her own values automatically trump that medical judgment? If the latter is the case, does that make the physician merely a contracted technician (provider) who must do as the patient (consumer) requests? Modern discussion of this old question is heavily overbalanced by the dominance given to patient autonomy, which ignores the significance of both physician autonomy and professionally mandated beneficence. By allowing physicians to declare a treatment "inappropriate" we have admitted our bias that there are some boundaries to medical practice and have implied that there are some norms to which physicians should adhere. This generic question has been well addressed by many others, and we do not claim any new insights. However, we wish to focus the question even more finely: Should the physician's judgment of "inappropriateness" trump the patient's religiously based judgment of "appropriateness"?

Wreen has proposed that religiously based treatment refusals are "special" because they are an expression of extrinsic values, rather than merely a personal preference. We believe that he is correct. Because a value is shared by the patient's community (ie is extrinsic by Wreen's definition) it should be given more weight than a patient's idiosyncratic choice. However, that alone should not make those shared values determinative. There are other extrinsic values (economic, political, cultural) which may also influence a patient to make a specific choice. What makes religious values "special" is not only that they are shared by a community, but more important, that they are incorporated by the individual into his or her persona. Religious values are thus more intrinsic than other shared values because they deal with the very meaning of life. In addition, we believe that this expanded concept of the "specialness" of religious values can be extended to treatment requests as well as treatment refusals.

The issues on which this paper has focused have all dealt with end of life questions. Certainly religious beliefs can be at the centre of other differences of opinion between patient/family and physician, but this area has been the most frequent in our experience. The question of religiously based demands for "inappropriate" treatment will clearly impinge upon the euthanasia debate. If lethal prescription or injection becomes accepted as "treatment", the religious/philosophical beliefs of the patient/family may well be at odds with the beliefs of individual physicians or with what we have called "the bounds of accepted medical practice". Thus resolution of such value differences may have even greater significance in the future.

The three monotheistic faith traditions are quite different from each other and each has many different theologies within its broad definition. They do, however, share the belief that human individuals are in relationship to God. Theology is reflection on that faith in God. In discussing the task of theology in relation to bioethics, McCormick rejects two extreme positions, first that faith gives concrete answers, and second that faith has no influence. ${ }^{11}$ He goes on to say that "Reason informed by faith is neither reason replaced by faith, nor reason without faith. It is reason shaped by faith".

We do not mean to suggest by using these cases that they are necessarily representative of the beliefs which might be encountered with others from these same faith traditions. There is not a univocal position on such issues from any of the major religious traditions.

\section{Management recommendations}

How should the clinician respond when a patient or family requests "inappropriate" treatment based on religious beliefs? As in all situations where there is disagreement about treatment options, good communication is the most important step towards resolution. The patient or family must clearly 
understand the medical situation. This may require repeated discussion, conversations with consultants, viewing of $\mathrm{x}$-rays or other clinical data, or other efforts familiar to most clinicians. A management conference, which includes the patient/family, primary physician, consultants, bedside nurses and others from the care-team, is often the best way to ensure that such communication happens.

While most clinicians recognise the importance of communicating the medical facts clearly to patients and families, and some are becoming more sensitive to cultural differences, ${ }^{12}$ many are less convinced of the importance of learning about and considering the religious beliefs of the patient, dismissing such beliefs as mystical and unscientific and therefore of no clinical importance. Contemporary medicine has unfortunately adopted from the surrounding Western culture a post-modern attitude which leads to the presumption that scientific discourse is "public" and theological discourse is "private". We believe that bringing these discussions into a more open forum may begin to help in their resolution.

In those situations where no one on the team belongs to the same or similar faith community, it may be helpful to involve a "religious interpreter" much as one would use a "cultural interpreter". ${ }^{12}$ This may be a hospital chaplain, the patient's own clergyperson or spiritual advisor, or some other individual familiar with the specific beliefs which have led to the conflict. This individual should serve as a consultant to the care-team and should be included in the management conference. Even when the careteam and the patient/family share common traditions and religious beliefs it may be beneficial to have a religious support person for the patient/family. This religious interpreter or support person may help to articulate the belief in question (sovereignty, omnipotence, etc) in such a way that both parties to the conflict may have a clear understanding of the issue. He or she may be able to convince the physician that the belief is valid and should be given serious consideration. If, on the other hand, the requestor's concept of the belief is incorrect or unorthodox, or if the faith community believes that the doctrine or principle in question may be flexible in its application, or that it is superseded by other beliefs (for example the finiteness of life, the importance of ministering to the suffering of the patient), it may be possible to dissuade the patient or family from their request.

\section{"Fox-hole religion"}

The religious interpreter may also help the care-team determine whether the belief in question is a longstanding and firmly held belief or whether it has been grasped by the individual as a way of arguing for "inappropriate" treatment which otherwise has no rational basis. Such "fox-hole religion" is probably as common in the ICU as it is on the battlefield.
Irresolvable conflicts based on religious beliefs are very difficult, and a few have gone to court. At least three lower courts and one appellate court in the US have upheld a family's right to demand treatment deemed medically "inappropriate" where it was reported in the popular press that the demands were based on religious beliefs. However, the actual court decisions were not based on religious beliefs but on best interests of the patient (Soloveichik, IL), ${ }^{13}$ family rights (Baby $\mathrm{L}, \mathrm{MA}$ ), ${ }^{+}$substituted judgment (Wanglie, $\mathrm{MN}$ ), ${ }^{14}$ and treatment of disabled persons (Baby K, VA). ${ }^{15}$ There is at least one similar statutory precedent in that the New Jersey law which allows physicians to declare death using neurological criteria contains a conscience clause which says that when a family's religious beliefs preclude acceptance of such criteria, these criteria may not be used to declare the patient dead. ${ }^{16}$ Legal precedents in other jurisdictions may well be different.

\section{Conclusion}

We believe that requests for "inappropriate" treatments based on strongly held, well-established religious beliefs should be given serious consideration and should not be quickly discounted as mystical or irrational. This serious consideration does not preclude continued discussion and efforts at persuasion based both on clinical data and religious arguments which are compatible with the requestor's belief system. We further believe that persistent requests based on deeply held religious beliefs should most often be honoured. However, we do not believe that such claims are absolute. We agree with others that professional integrity requires physicians occasionally to refuse to provide an intervention based on professional conscience ${ }^{3}$ or medical standards. ${ }^{17}$ We are unable to give clear guidance on when such a stance is professionally or theologically justifiable. However, we do maintain that before such a stance is taken, there should be thorough and compassionate discussion of the religious beliefs offered as justification for the request. In those rare instances where such a professional stance is taken, the physician should offer to transfer care to another physician. If transfer is not possible, or the family is unable to find a physician willing to accept the patient within a reasonable period of time, we believe it may rarely be justifiable for the physician to decide unilaterally to forgo the treatment in question.

We do not intend to imply that patients or families have the right to receive any "inappropriate" treatment as long as the demand is religiously based. In most situations, physician refusal to provide "medically inappropriate" treatment is professionally sound. Some treatments are "inappropriate" regardless of the reason for the request. Rather we are suggesting that treatment which the physician considers "inappropriate" for some individuals when based 
purely on personal preference may, in fact, be "appropriate" when based on a patient's religious belief.

If medicine is to avoid violating the integrity of patients, it must surely avoid violating their religious integrity. We must recognise that religion and medicine are intricately woven together, in that they deal with life and death and the ultimate meaning of life and death. Both disciplines profess to want to make individuals whole. When health care professionals are aware of their own religious beliefs and biases, they are better able to approach patients and their surrogates with sensitivity and understanding. Although their values may differ, they share the goal of providing whatever is best for the patient, and what is best for the patient includes his or her beliefs about the meaning of life and death.

\section{Acknowledgments}

The authors would like to thank Grace Hannon, $\mathrm{MD}$, for research assistance and David Larson, $\mathrm{PhD}$, Alan Verhey, $\mathrm{PhD}$, and John Kilner, $\mathrm{PhD}$, or helpful comments on earlier drafts of this manuscript.

Robert D Orr, MD, is Director of Clinical Ethics at Loma Linda University Medical Center, Loma Linda, California, USA. Leigh $B$ Genesen, $R N, B A$, is a Clinical Ethicist at the University of New Mexico Hospital, Alburquerque, New Mexico, USA.

\section{References}

1 deLeon DM, Genesen LB, Orr RD. Manuscript under review.

2 Schneiderman LJ, Jecker NS, Jonsen AR. Medical futility: its meaning and ethical implications. Annals of Internal Medicine 1990; 112: 949-54.

3 Paris JJ, Schreiber MD, Statter M, et al. Beyond autonomy - physicians' refusal to use life-prolonging extracorporeal membrane oxygenation. New England Fournal of Medicine 1993; 329: 354-7.

4 Paris JJ, Crone RK, Reardon F. Physicians' refusal of requested treatment: the case of Baby L. New England Fournal of Medicine 1990; 322: 1012-5.

5 Miles SH. Informed demand for "non-beneficial" medical treatment. New England fournal of Medicine 1991; 325: 512-5.

6 Blackhall LJ. Must we always use CPR? New England Fournal of Medicine 1987; 317: 1281-5.

7 Moore FD. The desperate case: CARE (costs, applicability, research, ethics). Fournal of the American Medical Association 1989; 261: 1483-4.

8 Stauch M. Rationality and the refusal of medical treatment: a critique of the recent approach of the English courts. Fournal of Medical Ethics 1995; 21: 162-5.

9 Wreen MJ. Autonomy, religious values, and refusal of lifesaving medical treatment. Fournal of Medical Ethics 1991; 17: 124-30.

10 Stith R. Toward freedom from value. In: On moral medicine. Lammers SE, Verhey A, eds. Grand Rapids, MI: William B. Eerdmans Publishing Company, 1987: ch 20.

11 McCormick RM. Theology and bioethics. Hastings Center Report 1989; 19(Mar/Apr): 5-11.

12 Orr RD, Marshall PA, Osborn J. Cross-cultural considerations in clinical ethics consultations. Archives of Family Medicine 1995; 4: 159-164.

13 Soloveichik v Rush-Presbyterian/St Luke's Hospital and Soloveichik Circuit Court, Chancery Division, Cook County, IL. 1989 Jan 19.

14 Miles SH. Informed demand for "non-beneficial" medical treatment. New England fournal of Medicine 1991; 325: 512-5.

15 In the Matter of Baby K, 832 F Supp 1022 (ED Va 1993)

16 Olick RS. Brain death, religious freedom, and public policy: New Jersey's landmark legislative initiative. Kennedy Institute of Ethics fournal 1991; 1: 275-88.

17 Annas GJ. Asking the courts to set the standard of emergency care - the case of Baby K. New England Journal of Medicine 1994; 330: 1542-5.

\section{News and notes}

\section{Congress: Computer Integrated Surgery in the Areas of Head and Spine}

A congress on Computer Integrated Surgery in the Areas of Head and Spine will be held from September 1-5 this year in Linz, Austria. It is being organised by the Society for the Advancement of Neurosurgical Science and Research.

The conference is aimed not only at neurosurgeons, ENT surgeons, craniofacial surgeons, neuroradiologists and engineers but also at philosphers.

One of the main issues will be the fact that the new technologies allow for possibilities which make it necessary to re-think the traditional framework of medical practice.

For further information please contact: Kurt Holl, MD (Congress Secretary), Neurosurgical Department, OÖ Landes-Nervenklinik WagnerJauregg, A-4020 Linz, Austria. Phone: +43-7326921-2124, fax: +43-732-6921-2811, email: cis@1kh-wj.or.at 